\title{
Progresso e controle da mela-das-sementes (Claviceps maximensis) de Brachiaria brizantha*
}

\author{
Carlos Eduardo Marchi ${ }^{1}$, Celso Dornelas Fernandes ${ }^{2,5}$, Fábio Coutinho Anache ${ }^{3} \&$ Larissa Rodrigues Fabris $^{4}$
}

${ }^{1}$ Laboratório Nacional Agropecuário/SP, Base Física de Jundiaí, CEP 13208-051, Jundiaí, SP, ${ }^{2}$ Embrapa Gado de Corte, CP 154, CEP 79002-970, Campo Grande, MS. ${ }^{3}$ Universidade para o Desenvolvimento do Estado e da Região do Pantanal (UNIDERP), CP 2153, CEP 79003-010, Campo Grande, MS; ${ }^{4}$ Universidade Federal do Mato Grosso do Sul, CP 549, CEP 79070-900; ${ }^{5}$ Professor colaborador da UNIDERP.

${ }^{1}$ Parte da Dissertação do terceiro autor apresentada à UNIDERP. (2006). Apoio: FUNDECT/CNPq.

Autor para correspondência: Celso Dornelas Fernandes. celsof@cnpgc.embrapa.br

Data de chegada: 11/10/2006. Aceito para publicação em: 15/04/2008

\section{RESUMO}

Marchi, C.E.; Fernandes, C.D.; Anache, F.C.; Fabris, L.A. Progresso e controle da mela-das-sementes (Claviceps maximensis) de Brachiaria brizantha. Summa Phytopathologica, v.34, n.3, p.241-247, 2008

Verificou-se a eficiência de uma ou duas aplicações de Piraclostrobin + Epoxiconazole, Mancozeb, Triadimenol, Azoxistrobin + Ciproconazole, Trifloxistrobin + Ciproconazole ou Tebuconazole no controle da mela-das-sementes de Brachiaria brizantha cvs. Marandu e Xaraés, durante a safra 2004-05. Também foram avaliados os indutores de resistência Acibenzolar-S-Metil e Silicato de Potássio (via aérea ou solo). Triadimenol, com uma ou duas aplicações, Piraclostrobin + Epoxiconazole, Azoxistrobin + Ciproconazole, Trifloxistrobin + Ciproconazole ou Tebuconazole, com duas aplicações, foram promissores no controle da mela-dassementes do capim-marandu. Já para a cv. Xaraés, melhor controle foi alcançado com o Piraclostrobin + Epoxiconazole, independente do número de aplicações, Triadimenol, Trifloxistrobin +
Ciproconazole ou Tebuconazole, com duas aplicações. Não houve correlação entre os dados de produção de sementes puras e a intensidade da mela. Com relação ao progresso da mela-das-sementes de $B$. brizantha cvs. Marandu e Xaraés, constatou-se que a doença manifestou-se em períodos frios associados à umidade relativa alta. $\mathrm{Na}$ cv. Marandu a doença ocorreu na fase final da cultura, enquanto que na cv. Xaraés, a mela foi detectada na fase de intenso florescimento. Foram constatados aumentos na intensidade da doença em ambas as cultivares. A mela-das-sementes ocorreu em $64 \%$ das panículas da cv. Marandu e em $81 \%$ das panículas da cv. Xaraés; cerca de $20 \%$ e $18 \%$ das flores/sementes, respectivamente, foram afetadas. Os resultados demonstraram existir correlação positiva entre os valores de incidência e severidade da mela.

Palavras -chave adicionais: Sphacelia sp., análise temporal, controle, braquiária.

\begin{abstract}
Marchi, C.E.; Fernandes, C.D.; Anache, F.C.; Fabris, L.A. Progress and control of honeydew (Claviceps maximensis) of Brachiaria brizantha. Summa Phytopathologica, v.34, n.3, p.241-247, 2008

The efficiency of one or two applications of Pyraclostrobin + Epoxyconazole, Mancozeb, Triadimenol, Azoxystrobin + Cyproconazole, Trifloxystrobin + Cyproconazole or Tebuconazole in the control of honeydew in seeds of Brachiaria brizantha cvs. Marandu and Xaraes was verified during crop 2004-05. The inductors of resistance Acibenzolar-S-Methyl and Potassium Silicate (applied in aerial part or in soil) were evaluated. Triadimenol, with one or two applications, Pyraclostrobin + Epoxyconazole, Azoxystrobin + Cyproconazole, Trifloxystrobin + Cyproconazole or Tebuconazole, with two applications, were the fungicides most promising in the control of disease in marandu grass. About cv. Xaraes, better control was reached with Pyraclostrobin + Epoxyconazole, independent of number of applications,

Triadimenol, Trifloxystrobin + Cyproconazole or Tebuconazole, with two applications. Correlation between production of pure seeds and of disease intensity was not detected. With regard to the progress of honeydew in seeds of B. brizantha cvs. Marandu and Xaraes, observed the disease occurred in cold periods with high humidity. In cv. Marandu the pathogen occurred in final phase of culture, while in cv. Xaraes the honeydew was detected in phase of intense bloom. Constant increases of disease intensity were observed in two genotypes. The honeydew occurred in $64 \%$ of panicles of cv. Marandu and in $81 \%$ of panicles of cv. Xaraes; about $20 \%$ and $18 \%$ of flowers/seeds, respectively, was affected. The results verified high positive correlation between the values of incidence and severity of disease.
\end{abstract}

Additional keywords: Sphacelia sp., temporal analysis, control, braquiária grass.

A crescente demanda por forrageiras tropicais tem impulsionado o desenvolvimento da indústria sementeira no Brasil. Atualmente, o país é considerado o maior produtor, consumidor e exportador de sementes
(3). A maior parte da produção de sementes (95\%) tem sido destinada ao comércio interno e o restante exportado, principalmente para países da América do Sul e Central (12). 
A maior parte das sementes de forrageiras comercializadas nos mercados interno e externo pertence ao gênero Brachiaria, sobretudo B. brizantha cv. Marandu (23). Apesar de relevante, a sustentabilidade do sistema de produção de sementes dessas gramíneas encontra-se ameaçada pela incidência de patógenos, os quais podem reduzir a produtividade e/ou qualidade do produto. Tal problema já tem sido constatado em campos de produção, principalmente em regiões onde se constata a ocorrência de mela-das-sementes.

O primeiro registro da mela-das-sementes de Brachiaria sp. foi feito por Fernandes et al. (10), em pastagem no Mato Grosso do Sul. A doença também foi relatada em sementes de B. decumbens no Rio de Janeiro (1) e Minas Gerais (19). Atualmente, é possível que a meladas-sementes de braquiária se encontre amplamente distribuída no Brasil, dada a falta de padrões de qualidade sanitária para as sementes de forrageiras destinadas ao comércio interno.

Baseado em caracteres morfológicos e gama de hospedeiro, o agente etiológico da mela-das-sementes de braquiária foi inicialmente descrito como Claviceps sulcata Langdon, forma perfeita de Sphacelia sp. (10). Contudo, análises de seqüências de rDNA dos isolados brasileiros patogênicos à $B$. brizantha têm demonstrado forte identidade com as seqüências de $C$. maximensis Theis (15). Estudos moleculares recentes têm confirmado a interação de C. maximensis e espécies de Brachiaria no Brasil (7).

Os sinais da doença caracterizam-se pela exsudação de gotas de coloração áurea, referidas como mela ou honeydew (11). No início, o exsudato é pegajoso e atrativo a insetos; posteriormente, torna-se mais consistente, podendo envolver toda a panícula e formar escleródios. A mela-das-sementes de Brachiaria sp. se manifesta sob condições de alta umidade e baixa temperatura associadas a frentes frias durante $o$ estádio de florescimento e maturação das sementes (25).

Reduções expressivas de produtividade e qualidade das sementes de Brachiaria sp. têm sido observadas em campos com elevada intensidade de mela (11). Além das perdas diretas, é possível que alcalóides produzidos pelo fungo provoquem intoxicação em animais, quando estes se alimentam de grãos ou pastos contaminados (11).

O controle de $C$. maximensis em Brachiaria sp. ainda não está definido. Acessos de Brachiaria sp. aparentemente resistentes à doença foram detectados (11), porém, cultivares com essa característica não estão disponíveis. Enquanto isso, tem sido dada ênfase ao controle químico da doença. A eficiência de fungicidas sistêmicos, por exemplo, aplicados na parte aérea de B. brizantha, foi avaliada por Verzignassi et al. (25). Os resultados alcançados não se mostraram consistentes, havendo a necessidade de estudos adicionais para avaliar a efetividade dessa estratégia.

Diante dos riscos que a mela representa para a produção de sementes de Brachiaria sp., sobretudo B. brizantha cv. Marandu, e da escassez de informações acerca dos fatores climáticos favoráveis à doença, objetivou-se analisar o progresso da doença, bem como reavaliar a eficiência da aplicação de fungicidas e de indutores de resistência em Brachiaria brizantha no controle da mela-das-sementes.

\section{MATERIAL E MÉTODOS}

Eficiência de fungicidas e de indutores de resistência no controle de $C$. maximensis

Na safra 2004-05 foram conduzidos dois experimentos em campos de produção de sementes da Embrapa Gado de Corte, visando-se avaliar a eficiência do controle químico da mela-das-sementes de Braquiária. Um experimento foi implantado na sede da instituição, em Campo Grande-MS, com B. brizantha cv. Xaraés, e o outro na Fazenda
Modelo da Embrapa, em Terenos-MS, com B. brizantha cv. Marandu. Nessas áreas, o solo foi preparado para o plantio e, de acordo com a análise química e as exigências nutricionais das forrageiras, corrigido e adubado.

O delineamento experimental utilizado foi blocos casualizados, com quatro repetições, e unidade experimental foi de 4 x $4 \mathrm{~m}$. A semeadura foi realizada empregando-se o espaçamento de 0,04 m e 0,8 $\mathrm{m}$ dentro e entre linhas, respectivamente.

Foram analisados os tratamentos (g de i.a./ha): 1 - Controle (água), 2 - Piraclostrobin + Epoxiconazole $(99,75+37,5), 3$ - Mancozeb (2000), 4 - Triadimenol (125), 5 - Azoxistrobin + Ciproconazole (60 +24), 6 - Trifloxistrobin + Ciproconazole $(75+32), 7$ - Tebuconazole (150), 8 - Acibenzolar-S-Metil (60) e 9 - Silicato de Potássio, aplicado na parte aérea das plantas (125) ou distribuído no solo (78.125), ambos na forma de calda.

Para a cv. Marandu, a aplicação dos tratamentos foi realizada no período correspondente ao terceiro pico de florescimento. Os produtos foram aplicados no elongamento das panículas (emborrachamento), ou no pico de florescimento, com ou sem reaplicação após 20 dias (Tabela 1). O pico de florescimento foi considerado quando $50 \%$ das panículas lançadas sofreram antese. Para a cv. Xaraés, os tratamentos foram aplicados no emborrachamento, referente ao primeiro pico de florescimento, durante o primeiro pico de florescimento ou no primeiro e segundo picos de florescimento, conforme descrito na Tabela 2. O intervalo entre as aplicações foi de 15 dias.

As aplicações foram realizadas com pulverizador costal pressurizado com $\mathrm{CO}_{2}$ e volume de calda de $300 \mathrm{~L} / \mathrm{ha}$. Utilizou-se um regador para a aplicação do Silicato de Potássio via solo, em volume correspondente a $6.250 \mathrm{~L}$ de calda por hectare.

Periodicamente, a eficiência dos produtos foi avaliada com base nos valores de incidência da mela-das-sementes. Para isso, foram amostradas 30 panículas no centro de cada parcela $\left(4 \mathrm{~m}^{2}\right)$, quantificando-se a porcentagem de panículas infectadas com mela em relação ao total (PPI). A partir dessas panículas, coletou-se uma subamostra de 10 unidades, avaliando-se a porcentagem de flores/sementes infectadas em relação ao número total (PFSI). Após a coleta dos dados, foram calculadas as áreas abaixo das curvas de progresso (AACP) da incidência da doença.

Ao final do ensaio conduzido com $B$. brizantha cv. Xaraés, procedeu-se a colheita das sementes pelo método de varredura, considerando-se apenas a área central de cada parcela. O beneficiamento das sementes foi realizado com o auxílio de peneiras e soprador, os quais removeram as impurezas mais grossas e as sementes "chochas", respectivamente. Amostras de $100 \mathrm{~g}$ de sementes brutas foram submetidas à análise de pureza, visando à determinação da produtividade de sementes puras.

Teste padrão de germinação das sementes foi conduzido em caixas tipo Gerbox, sobre papel de filtro, umedecido com solução de $\mathrm{KNO}_{3}$ a $0,2 \%$. Prepararam-se quatro Gerboxes (repetições) por tratamento, e, em cada um, foram distribuídas 100 sementes. Estas foram incubadas sob regime de alternância de temperatura e luminosidade $\left(15^{\circ} \mathrm{C}\right.$ sem luz $/ 8 \mathrm{~h}$ e $35^{\circ} \mathrm{C}$ com luz/16 h). A cada sete dias, foi calculada a porcentagem de sementes germinadas, sendo a última contagem realizada aos 28 dias após a incubação. Adicionalmente, realizou-se análise da viabilidade das sementes por meio do teste de tetrazólio. Para isso, amostras de 100 sementes foram embebidas em água durante $10 \mathrm{~h}$ e, em seguida, cada semente foi cortada transversalmente próximo ao embrião. A coloração foi feita com solução de tetrazólio (0,5\%) durante $4 \mathrm{~h}$. Para a avaliação, considerou-se como viável as sementes cujo embrião tornou-se colorido de vermelho. Aárea máxima permitida 
de tecido não colorido, flácido ou necrosado foi de $2 / 3$ da radícula, a partir de sua extremidade (4).

\section{Progresso da mela-das-sementes}

A partir dos índices de mela constatados no tratamento controle de ambos os experimentos, foram plotadas as curvas de progresso da doença, as quais foram confrontadas com as variáveis climáticas prevalecentes no período das avaliações da mela (maio a agosto de 2005). Tais informações foram coletadas na Estação Climatológica da Embrapa Gado de Corte, localizada na sede da instituição e aproximadamente a $9 \mathrm{Km}$ do ensaio instalado na Fazenda Modelo, em Terenos-MS. As variáveis consideradas foram precipitação, umidade relativa do ar e temperaturas máxima, média e mínima $\left({ }^{\circ} \mathrm{C}\right)$. Para temperatura e umidade relativa foram calculadas as médias dos sete dias que precederam à avaliação da doença, enquanto que para a precipitação, obteve-se o valor acumulado durante esse período.

\section{Análises dos dados}

As análises de variância e de correlação foram realizadas com o programa SAS (20). Para a comparação das médias, utilizou-se o teste de agrupamento Scott \& Knott (21), disponibilizado no programa Genes (8).

\section{RESULTADOS E DISCUSSÃO}

Eficiência de fungicidas e de indutores de resistência no controle de $C$. maximensis

A quantificação do PPI e PFSI no final do ensaio não permitiu discriminar os produtos aplicados em B. brizantha cv. Marandu quanto ao controle da mela-das-sementes (Tabela 1). Em contrapartida, quando se analisou o progresso temporal da mela, baseado nos valores de AACP, foi possível constatar a eficiência diferenciada dos produtos aplicados. Resultados similares foram observados no ensaio conduzido com a cv. Xaraés (Tabela 2).

Com algumas exceções, uma única aplicação de fungicida não promoveu eficiente redução da intensidade da mela-das-sementes de B. brizantha (Tabelas 1 e 2). Tal fato foi esperado, haja vista o florescimento prolongado e desuniforme do hospedeiro, o qual implica em maior período de suscetibilidade, e, conseqüentemente, na necessidade de aplicações adicionais. Além disso, é possível que os produtos aplicados, a maior parte sistêmicos, tenham exibido pequeno efeito residual, semelhante ao constatado por McLaren (13) com o patossistema sorgo-Claviceps sp.

Os fungicidas que mais se destacaram no controle da mela-dassementes do capim-marandu, considerando a AACP da PPI, foram Piraclostrobin + Epoxiconazole, Triadimenol, Azoxistrobin + Ciproconazole, Trifloxistrobin + Ciproconazole e Tebuconazole, quando aplicados duas vezes. Triadimenol apresentou eficiência no controle da doença mesmo quando aplicado em dose única (Tabela 1).

Por sua vez, foi observada menor ocorrência de mela nas plantas da cv. Xaraés submetidas a aplicações de Piraclostrobin + Epoxiconazole, Triadimenol, Trifloxistrobin + Ciproconazole ou Tebuconazole no primeiro e segundo picos de florescimento (Tabela 2). A associação de Piraclostrobin + Epoxiconazole também se destacou quando este produto foi aplicado apenas no primeiro pico de florescimento. Considerando a AACP da PFSI, se destacaram Piraclostrobin + Epoxiconazole e Triadimenol, independentes do número de aplicações, e Mancozeb, Azoxistrobin + Ciproconazole,

Tabela 1. Eficiência de fungicidas e de indutores de resistência no controle de Claviceps maximensis em flores/sementes de Brachiaria brizantha cv. Marandu. Terenos, MS (2004-05).

\begin{tabular}{|c|c|c|c|c|c|}
\hline Tratamentos & Número de aplicações & $\mathbf{P P I}^{1}$ & AACP da PPI ${ }^{2}$ & PFSI $^{3}$ & AACP da PFSI $^{4}$ \\
\hline Testemunha & - & $62,5^{*} \mathrm{a}$ & $201,4 \mathrm{a}$ & 19,6 a & $100,6 \mathrm{a}$ \\
\hline Piraclostrobin + Epoxiconazole & $1 X^{\delta}$ & $70,7 \mathrm{a}$ & $177,7 \mathrm{a}$ & 18,9 a & 84,2 a \\
\hline Mancozeb & $1 \mathrm{X}$ & 75,4 a & 165,6 a & 25,6 a & 99,0 a \\
\hline Triadimenol & $1 \mathrm{X}$ & 56,1 a & $138,8 \mathrm{~b}$ & 14,8 a & 77,1 a \\
\hline Azoxistrobin + Ciproconazole & $1 X$ & 75,9 a & 184,4 a & 25,5 a & 107,1 a \\
\hline Trifloxistrobin + Ciproconazole & $1 \mathrm{X}$ & 66,9 a & $180,1 \mathrm{a}$ & 26,6 a & 104,3 a \\
\hline Tebuconazole & $1 X$ & $65,4 \mathrm{a}$ & $167,2 \mathrm{a}$ & $21,5 \mathrm{a}$ & 88,5 a \\
\hline Silicato de Potássio (via aérea) & $1 \mathrm{X}$ & 71,6 a & $180,5 \mathrm{a}$ & 23,8 a & 98,2 a \\
\hline Piraclostrobin + Epoxiconazole & $2 X^{\delta}$ & 63,8 a & $144,5 \mathrm{~b}$ & 17,9 a & 81,0 a \\
\hline Mancozeb & $2 X$ & 66,6 a & 190,3 a & 18,5 a & 97,6 a \\
\hline Triadimenol & $2 \mathrm{X}$ & 35,6 a & $150,2 \mathrm{~b}$ & $11,0 \mathrm{a}$ & 82,4 a \\
\hline Azoxistrobin + Ciproconazole & $2 \mathrm{X}$ & 61,3 a & $120,8 \mathrm{~b}$ & 16,2 a & 68,2 a \\
\hline Trifloxistrobin + Ciproconazole & $2 X$ & 63,8 a & $147,4 \mathrm{~b}$ & 23,5 a & 93,4 a \\
\hline Tebuconazole & $2 X$ & 59,1 a & $125,0 \mathrm{~b}$ & $16,4 \mathrm{a}$ & 73,8 a \\
\hline Silicato de Potássio (via aérea) & $2 \mathrm{X}$ & 85,2 a & 215,3 a & 29,0 a & 128,8 a \\
\hline Acibenzolar-S-Metil & $1 \mathrm{X}(\mathrm{EP})^{\rho}$ & 78,5 a & $155,0 \mathrm{~b}$ & 33,1 a & 88,7 a \\
\hline Silicato de Potássio (via solo) & $1 \mathrm{X}(\mathrm{EP})$ & 68,7 a & $148,0 \mathrm{~b}$ & $22,0 \mathrm{a}$ & 79,7 a \\
\hline
\end{tabular}

${ }^{1}$ Porcentagem de panículas infectadas na última avaliação.

2 Área abaixo da curva de progresso da porcentagem de panículas infectadas com mela, com base em quatro avaliações.

${ }^{3}$ Porcentagem de flores/sementes infectadas na última avaliação.

${ }^{4}$ Área abaixo da curva de progresso da porcentagem de flores/sementes infectadas com mela, com base em quatro avaliações.

Aplicação durante o terceiro pico de florescimento (23/06/2005).

${ }^{\delta}$ Aplicação durante o terceiro pico de florescimento (23/06/2005) e reaplicação após 20 dias (13/07/2005).

${ }^{\circ}$ Aplicação durante elongamento das panículas (13/06/2005).

* Médias seguidas pela mesma letra na coluna não diferem entre si pelo teste de agrupamento Scott-Knott $(\mathrm{P} \geq 0,05)$. 
Trifloxistrobin + Ciproconazole e Tebuconazole, todos com duas aplicações (Tabela 2).

$\mathrm{O}$ potencial de fungicidas à base de Triadimenol e Azoxistrobin para o controle da mela-das-sementes de B. brizantha foi anteriormente observado por Capelari et al. (6). A eficiência de Tebuconazole também tem sido demonstrada no controle de Claviceps africana, agente causal da doença-açucarada do sorgo $(17 ; 18)$.

Com relação ao Acibenzolar-S-Metil, conhecido ativador de resistência de plantas à patógenos, observou-se efeito positivo apenas quando se considerou a AACP da PPI na cv. Marandu (Tabelas 1 e 2). Visto que o intervalo entre a aplicação do indutor e a infecção do patógeno constitui fator crucial para o sucesso da indução de resistência (22), é provável que o estado de indução das plantas da cv. Xaraés, por ocasião da ocorrência da doença, não foi suficiente para protegêlas. Também, é possível que o resultado negativo tenha sido reflexo de características intrínsecas do patossistema $B$. brizantha cv. Xaraés- $C$. maximensis.

Quanto ao Silicato de Potássio, verificou-se que a aplicação na parte aérea das plantas, preconizadas como eficientes no controle da mela por parte de produtores de sementes, não resultou em redução de $C$. maximensis em $B$. brizantha, independentemente do número de aplicações (Tabelas 1 e 2). Diante da habilidade dessa forrageira em acumular Si (14), é possível que a dose do produto aplicada não foi adequada para desencadear efetivamente os mecanismos de defesa pré e/ou pós-formados do hospedeiro. As hipóteses de período insuficiente para a ativação da resistência do hospedeiro e diluição do efeito protetor também não são descartadas.
Porém, quando aplicado ao solo, na pré-antese (elongamento das panículas), o Silicato de Potássio promoveu considerável redução da AACP da PPI em ambas as cultivares. Para B. brizantha cv. Xaraés também se constatou menor valor de AACP da PFSI (Tabela 2). Entretanto, sob o ponto de vista prático, essa estratégia não se mostra viável em virtude do grande volume de calda utilizado, exigindo grande disponibilidade de água e movimentação de máquinas. Ademais, requer grande quantidade de $\mathrm{Si}$, sobretudo devido às interações desse elemento com o solo.

Quando se confrontou os valores de AACP da PPI e da PSFI, obteve-se correlação positiva, tanto para a cv. Marandu $(\mathrm{r}=0,89 ; \mathrm{P}=$ $0,0001)$ quanto para a cv. Xaraés $(\mathrm{r}=0,92 ; \mathrm{P}=0,0001)$, indicando a possibilidade de utilização da incidência de panículas infectadas como variável independente em estudos da interação $B$. brizantha-C. maximensis.

Visto que $C$. maximensis incidiu em $B$. brizantha $\mathrm{cv}$. Marandu tardiamente, quando a maior parte das sementes produzidas já havia sofrido degrana, não se justificou analisar o impacto do patógeno na produtividade dessa gramínea. Já para a cv. Xaraés, em termos numéricos e com raras exceções, observaram-se melhores produções nas plantas submetidas às aplicações de fungicidas ou indutores de resistência (Tabela 2). No entanto, não se constatou correlação significativa entre os valores de AACP da PPI $(r=0,27 ; P=0,30)$ e da PFSI ( $\mathrm{r}=0,40 ; \mathrm{P}=0,11)$ e os dados de produção, o que necessita ser melhor investigado. Dado o caráter prejudicial de patógenos, esperavam-se melhores índices de produção nas plantas que exibiram menores níveis de doença, a exemplo do tratamento Piraclostrobin +

Tabela 2. Eficiência de fungicidas e de indutores de resistência no controle de Claviceps maximensis em flores/sementes de Brachiaria brizantha cv. Xaraés. Campo Grande, MS (2004-05).

\begin{tabular}{|c|c|c|c|c|c|c|}
\hline Tratamentos & Número de aplicações & $\mathbf{P P I}^{1}$ & AACP da PPI $^{2}$ & PFSI $^{3}$ & AACP da PFSI $^{4}$ & Produção ${ }^{5}$ \\
\hline Testemunha & - & $80,3^{*} \mathrm{a}$ & $194,9 \mathrm{a}$ & $17,6 \mathrm{a}$ & $105,3 \mathrm{a}$ & $87,3 \mathrm{~b}$ \\
\hline Piraclostrobin + Epoxiconazole & $1 X^{\delta}$ & 65,1 a & $161,4 \mathrm{~b}$ & 26,6 a & $92,5 \mathrm{~b}$ & 160,3 a \\
\hline Mancozeb & $1 X$ & 72,9 a & 176,8 a & $28,0 \mathrm{a}$ & 96,2 a & 144,4 a \\
\hline Triadimenol & $1 X$ & 70,1 a & 172,9 a & 27,5 a & 86,7 b & $80,3 \mathrm{~b}$ \\
\hline Azoxistrobin + Ciproconazole & $1 \mathrm{X}$ & 70,2 a & 179,5 a & 34,3 a & 99,8 a & 226,5 a \\
\hline Trifloxistrobin + Ciproconazole & $1 X$ & 77,5 a & 188,9 a & $34,0 \mathrm{a}$ & $101,6 \mathrm{a}$ & 157,1 a \\
\hline Tebuconazole & $1 X$ & 76,4 a & $212,7 \mathrm{a}$ & 39,2 a & 114,8 a & 155,2 a \\
\hline Silicato de Potássio (via aérea) & $1 \mathrm{X}$ & 84,3 a & 192,9 a & 33,4 a & $95,8 \mathrm{a}$ & $87,4 \mathrm{~b}$ \\
\hline Piraclostrobin + Epoxiconazole & $2 X^{\delta}$ & $69,2 \mathrm{a}$ & $145,5 \mathrm{~b}$ & 30,6 a & $80,6 \mathrm{~b}$ & $128,2 \mathrm{~b}$ \\
\hline Mancozeb & $2 X$ & $66,1 \mathrm{a}$ & 180,8 a & $31,4 \mathrm{a}$ & 89,6 b & 193,6 a \\
\hline Triadimenol & $2 X$ & 57,7 a & $148,7 \mathrm{~b}$ & 24,6 a & $81,3 \mathrm{~b}$ & $105,1 \mathrm{~b}$ \\
\hline Azoxistrobin + Ciproconazole & $2 \mathrm{X}$ & 73,3 a & 172,0 a & 28,1 a & $90,6 \mathrm{~b}$ & $115,3 \mathrm{~b}$ \\
\hline Trifloxistrobin + Ciproconazole & $2 X$ & 52,6 a & $129,0 \mathrm{~b}$ & $24,4 \mathrm{a}$ & $74,8 \mathrm{~b}$ & $116,5 \mathrm{~b}$ \\
\hline Tebuconazole & $2 X$ & 72,3 a & $156,9 \mathrm{~b}$ & $26,7 \mathrm{a}$ & $78,5 \mathrm{~b}$ & $121,4 \mathrm{~b}$ \\
\hline Silicato de Potássio (via aérea) & $2 \mathrm{X}$ & $62,4 \mathrm{a}$ & 187,6 a & 26,3 a & $106,3 \mathrm{a}$ & 189,5 a \\
\hline Acibenzolar-S-Metil & $1 \mathrm{X}(\mathrm{EP})^{\rho}$ & 70,6 a & 192,5 a & $40,5 \mathrm{a}$ & $102,8 \mathrm{a}$ & 184,6 a \\
\hline Silicato de Potássio (via solo) & $1 \mathrm{X}(\mathrm{EP})$ & 64,0 a & $162,3 b$ & $29,1 \mathrm{a}$ & $88,7 \mathrm{~b}$ & $120,6 \mathrm{~b}$ \\
\hline
\end{tabular}

${ }^{1}$ Porcentagem de panículas infectadas na última avaliação.

2 Área abaixo da curva de progresso da porcentagem de panículas infectadas com mela, com base em quatro avaliações.

${ }^{3}$ Porcentagem de flores/sementes infectadas na última avaliação.

${ }^{4}$ Área abaixo da curva de progresso da porcentagem de flores/sementes infectadas com mela, com base em quatro avaliações.

${ }^{5}$ Produção de sementes puras (Kg/ha).

${ }^{\varphi}$ Aplicação durante o primeiro pico de florescimento (21/06/2005).

${ }^{\delta}$ Aplicação durante o primeiro (21/06/2005) e segundo picos de florescimento (06/07/2005).

${ }^{\circ}$ Aplicação durante elongamento das panículas (11/06/2005).

* Médias seguidas pela mesma letra na coluna não diferem entre si pelo teste de agrupamento $\mathrm{Scott}-\mathrm{Knott}(\mathrm{P} \geq 0,05)$. 

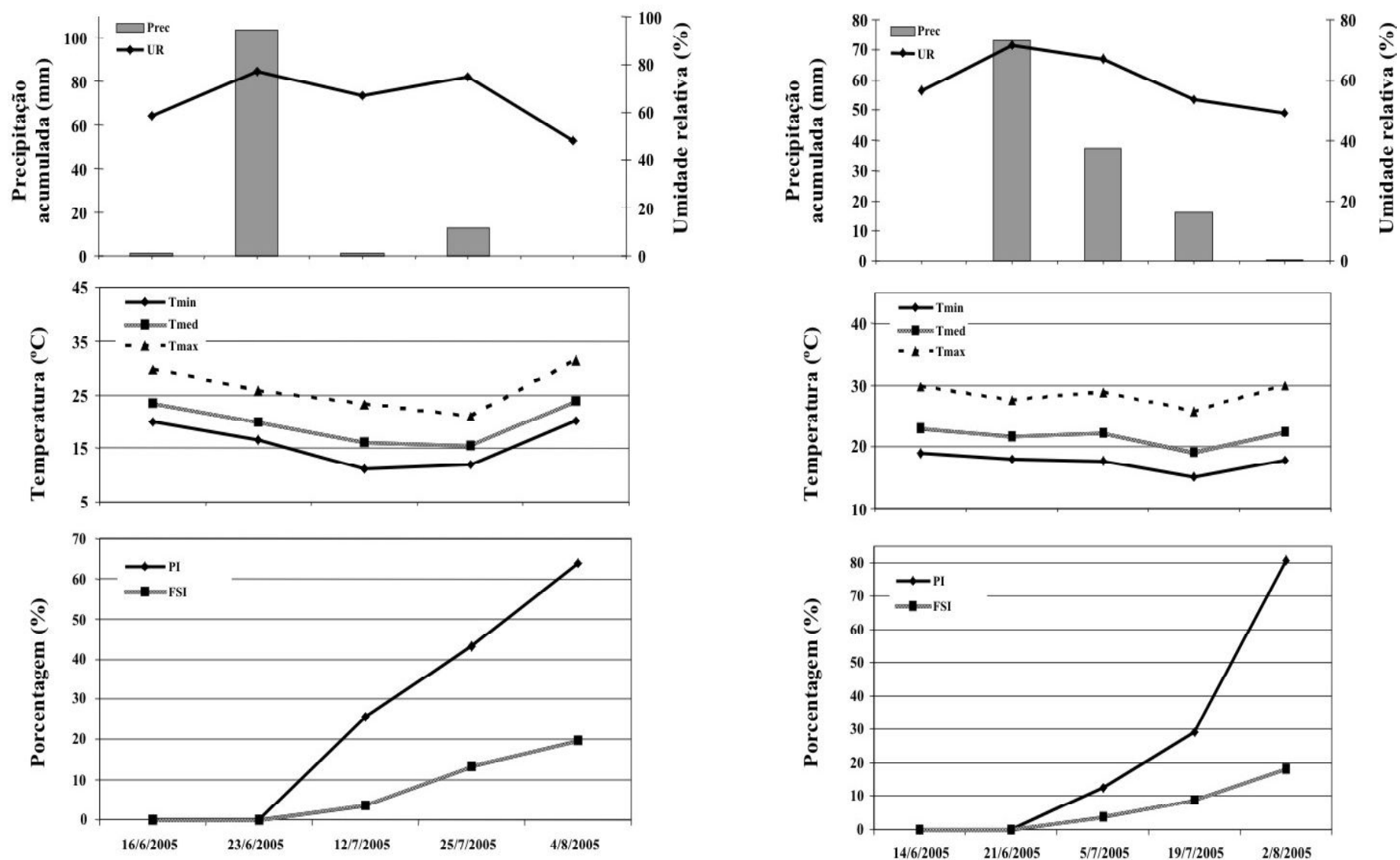

Tempo

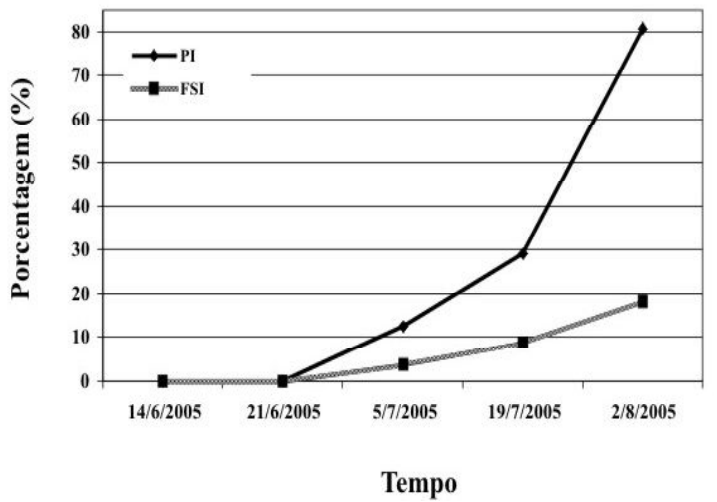

Figura 1. Progresso da porcentagem de panículas (PPI) e de flores/sementes (PFSI) de Brachiaria brizantha infectadas com Claviceps maximensis, na safra 2004-05. A. Cultivar Marandu, conduzida em Terenos, MS. B. Cultivar Xaraés, conduzida em Campo Grande, MS. Tmin: temperatura mínima; Tmed: temperatura média; Tmax: temperatura máxima; Prec: precipitação; UR: umidade relativa.

Epoxiconazole, aplicado em dose única (Tabela 2).

A utilização de duas aplicações de Silicato de Potássio na parte aérea da cv. Xaraés, apesar de não prevenir a infecção de C. maximensis, resultou em produção superior à testemunha (Tabela 2), talvez como reflexo de possível efeito nutricional do produto, visto que sua composição apresentou macro e micro-elementos.

Em relação à germinação e viabilidade das sementes, não houve diferenças dos tratamentos em relação à testemunha, comprovando que nenhum produto utilizado nas condições experimentais interferiu sobre essas variáveis. Em geral, as médias de germinação e viabilidade das sementes provenientes das plantas tratadas ficaram entre $32-50 \%$ e $70-81 \%$, respectivamente.

Os produtos mais promissores, como Triadimenol, Piraclostrobin + Epoxiconazole, Trifloxistrobin + Ciproconazole e Tebuconazole, bem como outros princípios ativos, serão submetidos a avaliações posteriores com o intuito de analisar seus potenciais em condições de elevado nível de doença. Adicionalmente, será verificado o efeito de aplicações de fungicidas no estádio de elongamento das panículas do hospedeiro, estratégia que tem prevenido a infecção do patógeno em B. brizantha na Colômbia (16).

Progresso da mela-das-sementes em $B$. brizantha

Não foi constatada a presença de $C$. maximensis durante o período de intenso florescimento de B. brizantha cv. Marandu (fevereiro a maio de 2005). Segundo Verzignassi et al. (25), a mela é favorecida por alta umidade e baixa temperatura durante o estádio de florescimento e maturação das sementes, o que implica em maior ocorrência no final do verão e início do outono (11). Assim, embora a umidade no referido período fosse adequada à ocorrência e ao progresso da doença, as altas temperaturas possivelmente foram fatores limitantes.

Com a permanência da forrageira no campo, foi possível detectar a mela nas flores/sementes do capim-marandu, cujos primeiros sinais se observaram a partir do final de junho de 2005, quando houve condições favoráveis à doença (Figura $1 \mathrm{~A}$ ). Ao longo da condução do ensaio, constatou-se na cv. Marandu o aumento da PPI por $C$. maximensis, a qual atingiu o máximo de $64 \%$. O progresso da incidência da mela foi garantido pela manutenção da umidade relativa do ar e das temperaturas amenas. Também se constatou aumento da PFSI por $C$. maximensis, o qual, no final do experimento, afetou cerca de $20 \%$ das flores/sementes contidas nas panículas (Figura 1A). As avaliações da intensidade de mela foram finalizadas na primeira semana de agosto, visto que, a partir daí, a maior parte das sementes sofreram degrana.

Ao contrário do capim-marandu, a cv. Xaraés apresenta florescimento tardio, concentrado nos meses de maio-junho (9). Como nesse período as condições climáticas foram favoráveis à infecção do patógeno, foi possível verificar a mela-das-sementes ainda na fase de 
intenso florescimento dessa forrageira. Os primeiros sinais de $C$. maximensis foram observados a partir do final de junho de 2005 (Figura 1B). Constatou-se o aumento da PPI e PFSI ao longo do ensaio, as quais atingiram o máximo de $81 \%$ e $18 \%$, respectivamente. Assim como no experimento anterior, as avaliações da intensidade de mela foram finalizadas na primeira semana de agosto, vista a generalizada degrana das sementes.

Analisando-se a Figura 1, tem-se a falsa impressão de aumento dos níveis de doença nas cultivares de braquiária com a diminuição dos índices pluviométricos. Isto se deve ao fato que em condições de precipitação excessiva ocorre a escorrimento da mela associada às sementes infectadas, dificultando assim a detecção dos sinais. Contudo, a disponibilidade de água parece ser fundamental para a ocorrência da doença e dispersão do patógeno (24). Observa-se também que, aparentemente, houve influência positiva da queda da temperatura no progresso de C. maximensis, o que corrobora com as observações de Verzignassi et al. (25). No entanto, não foi demonstrado com clareza o papel regulatório dos fatores do ambiente na interação $B$. brizantha-C. maximensis, o que é imprescindível para subsidiar a elaboração de futuros modelos de previsão da doença. Para ambas as cultivares, não se evidenciou correlação significativa entre as variáveis climáticas e a intensidade da mela-das-sementes.

Foi evidenciada correlação entre os valores de PPI e PFSI por $C$. maximensis, tanto para a cv. Marandu $(\mathrm{r}=0,98 ; \mathrm{P}=0,01)$ quanto para a cv. Xaraés $(\mathrm{r}=0,99 ; \mathrm{P}=0,01)$. Assim, de acordo com Campbell e Madden (5) e Amorim (2), é possível utilizar a incidência, variável mais prontamente quantificável, como variável independente em estudos para a avaliação da mela-das-sementes de braquiária.

\section{REFERÊNCIAS BIBLIOGRÁFICAS}

1. Alves, D.B.; Barreto, R.W.; Akiba, F. Ocorrência de "ergot" causado por Claviceps sulcata em pastagens de Brachiaria decumbens no Estado do Rio de Janeiro. Fitopatologia Brasileira, Brasília, v.18, supl., p.281-281, 1993. (Resumo).

2. Amorim, L. Avaliação de doenças. In: Bergamin Filho, A.; Kimati, H.; Amorim, L. (Ed.). Manual de fitopatologia. 3. ed. São Paulo: Agronômica Ceres, 1995. v. 1, p.647-671.

3. Andrade, C.M.S. de; Valentim, J.F. A síndrome da morte do capimbraquiarão. 2004. Disponível em: <http://www.beefpoint.com.br/ $\mathrm{bn} / \mathrm{rad}$ arestecnicos/artigo. as p ? n v $=1 \&$ area $=16 \&$ area_desc $=$ Pastagens\&id_artigo=19327\&perM=2\&perA=2006>. Acesso em: 11 de fev. de 2006.

4.Brasil. Ministério da Agricultura e Reforma Agrária. Secretaria Nacional de Defesa Agropecuária. Regras para Análise de Sementes. Brasília, 1992. 365 p.

5. Campbell, C. L.; Madden, L. V. Introduction to plant disease epidemiology. New York: J. Wiley, 1990. 532p.

6. Capelari, J.B.; Verzignassi, J.R.; Fernandes, C.D.; Barbosa, V.K.C.; Ocampos, R.K.; Ferreira, A.S.; Souza, F.H.D. Efeitos de fungicidas no controle da mela-das-sementes em Brachiaria brizantha cv. Marandu. Fitopatologia Brasileira, Fortaleza, v. 26, supl., p-423-424, 2001. (Resumo).

7. Chaves, Z.M.; Gomes, E.A.; Marriel, I.E.; Pfenning, L.H. Morphological and molecular characterization of Claviceps isolates from Sorghum bicolor, Brachiaria brizantha, B. decumbens and Panicum maximum in Brazil. Fitopatologia Brasileira, Fortaleza, v.29, supl., p.252-252, 2004. (Resumo).
8. Cruz, C.D. Programa Genes. * Versão Windows. * Aplicativo Computacional em Genética e Estatística. Viçosa:UFV, 2001. 648 p.

9. Embrapa. Brachiaria brizantha cv. Xaraés. 2004. Disponível em: <http://www.cnpgc. embrapa.br/produtoseservicos/pdf/ xaraes.pdf $>$. Acesso em: 23 de ago. de 2006.

10. Fernandes, C.D.; Fernandes, A.T.F; Bezerra, J.L. Honeydew of Brachiaria seed: a new disease for Brazil. Fitopatologia Brasileira, Brasília, v.17, supl., p.218-218, 1992. (Resumo).

11. Fernandes, C.D.; Fernandes, A.T.F; Bezerra, J.L. "Mela": uma nova doença e, sementes de Brachiaria spp. no Brasil. Fitopatologia Brasileira, Brasília, v.20, n.3, p.501-503, 1995.

12. Fernandes, C.D.; Marchi, C.E.; Jerba, V.F.; Borges, M.F. Patógenos Associados às Sementes de Forrageiras Tropicais e Estratégias de Controle. In: Zambolim, L. Sementes: qualidade fitossanitária. Viçosa: UFV, 2005. p.197-197.

13. Mclaren, N. W. Effect of sugary disease exudats on germination, seedling development and predisposition to seedling disease of sorghum (Sorghum bicolor). Plant Growth Regulation, New York, v.10, n.1, p.99-107, 1993.

14. Melo, S.P. de, Korndörfer, G.H., Korndörfer, C.M., Lana, R.M.Q.; Santana, D.G. de. Silicon accumulation and water deficit tolerance in Brachiaria grasses. Scientia Agricola, Piracicaba, v.60, p.755-759, 2003.

15. Pažoutová, S. Evolutionary strategy of Claviceps. In: White JF, Bacon CW, Hywel-Jones NL (Ed.). Clavicipitalean fungi: evolutionary biology, chemistry, biocontrol and cultural impacts. New York: Marcel Dekker, 2002. p.329-354.

16. Pineda L., B.; Balcázar, M.S.; Rivera C., Á.L. Evaluación de fungicidas para el controle complejo fungoso Drechslera spp., Phoma spp., Sphacelia sp., Epiccocum spp. (Cerebella spp.) en inflorescencias de Brachiaria brizantha (Panicoideae, Poaceae). Fitopatologia Colombiana, Cali, v.26, n.1, p.13-19, 2002.

17. Pinto, N. F. J. Controle químico da "ergot" (Claviceps africana Frederickson, Mantle \& de Milliano) ou doença-açucarada e das principais doenças foliares do sorgo (Sorghum bicolor (L.) Moench). Ciência e Agrotecnologia, Lavras, v.27, n.4, p.939944, 2003.

18. Pinto, N. F. J.A.; Ferreira, A. S.; Casela, C. R. Ergot (Claviceps africana) ou doença-açucarada do sorgo. Circular Técnica. Embrapa-CNPMS, Sete Lagoas, n. 23, 1997. 24 p.

19. Pozza, E.A.; Pomella, A.W.V.; Souza, P.E. Doenças associadas a pastagens e forrageiras na região de Larvas (MG-Brasil), de março/1992 a março/1993. Fitopatologia Brasileira, Brasília, v.19, supl., p.276-277, 1994. (Resumo).

20. SAS Institute. SAS/STAT Software: changes and enhancements through release 9.1. New York: Cary, 2003.

21. Scott, A.J.; Knott, M.A. Cluster analysis method for grouping means in the analysis of variance. Biometrics, Washington, v.30, n.3, p.507-512, 1974.

22. Van Loon, L.C., Bakker, P.A.H.M. \& Pieterse, C.M.J. Systemic resistance induced by rhizosphere bacteria. Annual Review of Phythopathology, Palo Alto, v.36, p.453-483, 1998.

23. Vechiatto, M.H. Sanidade de Sementes de Gramíneas Forrageiras. In: SIMPÓSIO BRASILEIRO DE PATOLOGIA DE SEMENTES, 8., 2004. João Pessoa. Anais. João Pessoa: UFPB, 2004. p.5557.

24. Verzignassi, J.R.; Fernades, C.D. Doenças em forrageiras. Gado de Corte Divulga, Campo Grande, n.50, 2001. 2p.

25. Verzigassi, J.R.; Souza, F.H.D. De; Fernandes, C.D.; Carvalho, J.; Barbosa, M.P.F.; Barbosa, O.S.; Vida, J.B. Estratégias de controle da mela em área de produção de sementes de Brachiaria brizantha cv. Marandu. Summa Phytopathologica, Botucatu, v.29, n.1, p.66-66, 2003. (Resumo). 